Jurnal Abdidas Volume 2 Nomor 4 Tahun 2021 Halaman 969-974

JURNAL ABDIDAS

http://abdidas.org/index.php/abdidas

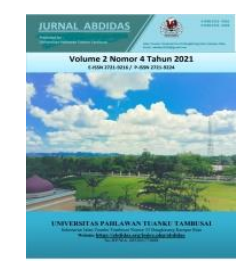

\title{
Peduli Lingkungan dari Pencemaran Sampah Plastik di Kawasan Lembanna
}

\author{
Rahmatia Thahir $^{1 \varpi}$, Nurul Fadhilah $^{2}$, Nurdiyanti $^{3}$, Nurul Magfirah $^{4}$, Anisa $^{5}$ \\ Pendidikan Biologi, Universitas Muhammadiyah Makassar, Indonesia $a^{1,2,3,4,5}$ \\ E-mail: rahmatiah.thahir@unismuh.ac.id ${ }^{1}$,nurul.fadhilah@unismuh.ac.id ${ }^{2}$, nurdiyanti@unismuh.ac.id ${ }^{3}$, \\ nurul.magfirah@unismuh.ac.id ${ }^{4}, \underline{\text { anisa@ unismuh.ac.id }}{ }^{5}$
}

\begin{abstract}
Abstrak
Kegiatan ini adalah kegiatan Pengabdian kepada Masyarakat (PKM) dengan kepedulian terhadap lingkungan dari pencemaran sampah plastik dimulai dari kedasaran diri sendiri untuk tidak membuang sampah sembarangan dan mengurangi penggunaan yang berbahan plastik dalam kehidupan sehari-hari. Tujuan kegiatan ini adalah kepedulian terhadap lingkungan dari pencemaran sampah plastik. Mahasiwa sebagai agen perubahan dan kontrol sosial masyarakat sehingga harus terus diberikan motivasi akan sadar dan peduli lingkungan sehingga terhindar dari pencemaran. Pengabdian kepada masyarakat ini dilaksanakan di lokasi Camp Lembanna Tinggimoncong Kabupaten Gowa, pada tanggal 20 Januari 2019. Penyampaian materi dilakukan secara langsung dengan pembagian brosur kepada mahasiswa, wisatawan umum dan masyarakat yang berjualan di dalam kawasan Lembanna. Kegiatan telah dilakukan dengan 3 tahap yaitu tahap persiapan dengan melakukan observasi keadaan lingkungan di kawasan Lembanna; tahan pelaksanaan dengan kegiatan penyuluhan pencegahan pencemaran lingkungan dari sampah plastik; dan tahap evaluasi dengan melakukan pembersihan dan pengumpulan sampah di sekitar kawasan wisata Lembanna.
\end{abstract}

Kata kunci: peduli lingkungan, pencemaran, sampah plastik

\begin{abstract}
This activity is a community service activity by concern for the environmental pollution from plastic waste pollution starts from the basics of oneself not to throw away trash, and reduce the use of plastics in everyday. The purpose of this activity is by concern for the environmental pollution from plastic waste pollution. Students as agents of change and social control of the community so that they must continue to be motivated to be aware and care about the environment so as to avoid pollution. This community service was carried out at the Lembanna Tinggimoncong Camp location, Gowa Regency, on January 20, 2019. Submission of material was carried out directly by distributing brochures to students, general tourists and the public who sell in the Lembanna area. The activity has been carried out in 3 stages, namely the preparation stage by observing environmental conditions in the lembanna area; hold the implementation with outreach activities on the prevention of environmental pollution from plastic waste; and the evaluation stage by cleaning and collecting garbage around the Lembanna tourist area.
\end{abstract}

Keywords: enveronmental care, pollution, plastic waste

Copyright (c) 2021 Rahmatia Thahir, Nurul Fadhilah, Nurdiyanti' Nurul Magfirah, Anisa

$\triangle$ Corresponding author

Address : Jalan Sultan Alauddin No. 259 Makassar

Email : rahmatiah.thahir@unismuh.ac.id

DOI : https://doi.org/10.31004/abdidas.v2i4.406

ISSN 2721- 9224 (Media Cetak)

ISSN 2721- 9216 (Media Online) 
970 Peduli Lingkungan dari Pencemaran Sampah Plastik di Kawasan Lembanna - Rahmatia Thahir, Nurul Fadhilah, Nurdiyanti Nurul Magfirah, Anisa

DOI: https://doi.org/10.31004/abdidas.v2i4.406

\section{PENDAHULUAN}

Sampah tidak dapat lepas dari kehidupan manusia. Hal ini dikarenakan manusia menghasilkan sampah dalam kehidupan dan kegiatan sehari-hari. Sampah-sampah tersebut berasal dari kegiatan rumah tangga dan industri, baik berupa sampah organik maupun anorganik (Asmawati et al., 2019). Komposisi sampah Indonesia berupa sampah organik seperti sisa makanan, kayu, ranting daun sebesar 57\%, sampah plastik sebesar 16\%, sampah kertas 10\%, serta sampah lainnya seperti logam, kain tekstil, karet kulit, dan kaca sebesar 17\%. Salah satu jenis sampah yang paling lambat terurai adalah sampah plastik yang bisa mencapai 400 tahun. Total timbunan sampah plastik $16 \%$ dari total timbunan sampah nasional. Hanya 5\% dari sampah plastik yang didaur ulang dengan efektif, sementara $40 \%$ lainnya di Tempat Pembuangan Akhir (TPA) sampah dan sisanya berakhir di ekosistem seperti lautan (Karnelasatri, 2019).

Plastik terbuat dari petrikimia. Zat-zat kimia ini tidak layak kembali ke ekologi di sekitar kita. Plastik yang berceceran, dibakar, atau dibuang teurai menjadi zat-zat kimia beracun. Zat kimia ini larut ke tanah, air dan udara yang kemudian diserap oleh tumbuhan dan hewan yang pada akhirnya bisa menyebabkan penyakit pada manusia (Istirokhatun \& Nugraha, 2019).

Masyarakat perlu memiliki kesadaran tentang dampak sampah plastik, mengurangi pemakaian dan pengelolaan dengan tepat. Kesadaran tersebut diharapkan dapat mengurangi jumlah sampah yang harus dibuang ke TPA ataupun berakhir di ekosistem (Mahyudin, 2017).
Edukasi tentang pengurangan penggunaan plastik dapat dilakukan sedini mungkin dan dimulai diri sendiri, kemudian ke orang lain. Faktor penyebab kepedulian lingkungan didasari cara berpikir dan perilaku manusia. Upaya menjaga lingkungan harus bermula dari diri sendiri dengan melakukan hal-hal kecil (Asteria \& Heruman, 2016). Mahasiswa sebagai agen perubahan yang selalu berada di tengah-tengah masyarakat maka harus melakukan perubahan perilaku untuk menjaga kelestarian lingkungan dan jauh dari pencemaran. Sebagian besar dari mahasiswa pendidikan biologi FKIP Universitas Muhammadiyah Makassar memiliki kegemaran untuk melakukan aktivitas di alam bebas seperti ke gunung dengan tujuan camping, mendaki, atau sekedar jalan-jalan atau berwisata. Kegiatan tersebut yang berpotensi menghasilkan sampah plastik sebagai pembungkus makanan yang mereka bawah.

Berdasarkan hasil observasi tim PKM di kawasan wisata Lembanna atau pendakian kaki Gunung Bawakaraeng yang terletak di Tinggimoncong Kabupaten Gowa Sulawesi Selatan, yang sebelumya telah berkoordinasi dengan Bapak Hamzah sebagai kepala lingkungan Lembanna menunjukkan bahwa banyak sampahsampah plastik yang ditinggalkan pemiliknya di area-area camp dan jalur pendakian sehingga nampak kotor dan tidak nyaman. Sampah plastik seperti pembungkus mie, pembungkus biskuit, pembungkus kopi, kantong plastik, botol plastik, punting rokok, dan lain-lain. Padahal seharusnya sampah tersebut dibuang di tempat sampah atau di bawah pulang yang dapat mencemari lingkungan. 
971 Peduli Lingkungan dari Pencemaran Sampah Plastik di Kawasan Lembanna - Rahmatia Thahir, Nurul Fadhilah, Nurdiyanti Nurul Magfirah, Anisa

DOI: https://doi.org/10.31004/abdidas.v2i4.406

Pihak pengelola pun telah menyampaikan kepada wisatawan untuk tidak membuang sampah sembangan, namun kenyataannya para pengunjung acuh akan hal tersebut. Wisatawan datang dari berbagai di Sulawesi Selatan dengan kalangan yang berbeda seperti pejabat, pekerja kantoran, guru, siswa, dosen, mahasiswa dan masyarakat umum lainnya. Sebagian besar pengunjung adalah mahasiswa yang berasal dari Universitas di Makassar dan sekitarnya, termasuk Mahasiswa Pendidikan Biologi FKIP Universitas Muhammadiyah Makassar.

Berdasarkan uraian di atas, maka tim pelaksana melakukan kegiatan pengabdian kepada masyarakat dengan memberdayakan mahasiswa untuk mencegah pemcemaran lingkungan dengan membersihkan atau memungut sampah di kawasan Lembanna. Hal ini merupakan edukasi kepada mahasiswa dan pengunjung dengan pendekatan pembinaan secara langsung dengan istilah memberdayakan masyarakat (empowernment).

Adapun tujuan dilaksanakannya kegiatan PKM ini adalah untuk menambah kepedulian terhadap lingkungan dari pencemmaran sampah plastik. Luaran yang dihasilkan dalam pelaksanaan kegiatan PKM ini adalah bertambahnya kesadaran masyarakat tentang pentingnya menjaga lingkungan dari pemcemaran sampah plastik.

\section{METODE}

Kegiatan pengandian kepada masyarakat mengenai peduli lingkungan dari pencemaran sampah plastik khususnya di kawasan Lembanna Kecamatan Tinggimoncong Kabupaten Gowa. Kegiatan ini terdiri dari beberapa tahapan yaitu: 1) tahap persiapan, 2) tahap pelaksanaan, dan 3) tahap evaluasi.

Secara rinci tahapan kegiatan pengabdian kepada masyarakat dengan kepedulian terhadap lingkungan dalam mencegah pencemaran sampah plastik sebagai berikut:

\section{Tahap Persiapan}

Pada tahapan pertama kegiatan pengabdian ini adalah tahap persiapan. Tahap ini sangat menunjang kesuksesan kegiatan, maka dari itu segala bentuk hal yang dibutuhkan harus dipersiapkan dengan matang. Tahap ini dilakukan sebelum pelaksanaan kegiatan pengabdian di kawasan Lembanna. Tahapan ini antara lain: a) mengumpulkan informasi di lapangan berupa kondisi kawasan kaki Gunung Bawakaraeng yang biasa dijadikan sebagai tempat camp, jenis sampah, dan ketersediaan tempat sampah. Semua informasi yang ditemukan kemudian dikumpulkan sebagai bahan perencanaan kegiatan.

2. Tahap Pelaksanaan

Pada tahap pelaksanaan ini dilakukan pengabdian kepada masyarakat yang berupa kepedulian terhadap lingkungan dari percemaran dari sampah plastik bentuk dari mengedukasi masyarakat tentang dampak negatif dari sampah plastik. Kegiatan ini dilaksanakan pada hari Ahad, tanggal 20 Januari 2019 bertempat di lokasi Base Camp Lebanna Kaki Gunung Bawakaraeng, Tinggimoncong Kabupaten Gowa. Teknik pelaksanaan berupa penyampaian materi tentang pencegahan pencemaran lingkungan akibat sampah plastik. Kegiatan penyuluhan ini dilakukan dengan pemberian materi secara langsung dengan menggunakan media berupa brosur. Brosur 
972 Peduli Lingkungan dari Pencemaran Sampah Plastik di Kawasan Lembanna - Rahmatia Thahir, Nurul Fadhilah, Nurdiyanti Nurul Magfirah, Anisa

DOI: https://doi.org/10.31004/abdidas.v2i4.406

tersebut dibagikan langsung ke mahasiswa, ke pengunjung/ wisatawan, dan masyarakat setempat yang berjualan makanan di dalam kawasan Camp Lembanna. Kegiatan ini dibuka langsung oleh Bapak Hamzah selaku kepala lingkungan Lembanna. Kemudian dilanjutkan dengan pemaparan materi oleh Dosen Universitas Muhamamdiyah Makassar. Adapun jumlah peserta yang mengikuti kegiatan penyuluhan sekitar 38 orang.

\section{Tahap Evaluasi}

Setelah kegiatan penyuluhan mencegah pencemaran lingkungan dari sampah plastik, tahap selanjutnya yaitu evaluasi yang dilakukan oleh tim PKM. Di mana dosen, bapak kepala lingkungan, mahasiswa, dan masyarakat yang ingin juga berpartisipasi membersihkan dan mengumpulkan sampah plastik kemudian ditempatkan pada tempat sampah. Sampah yang tidak termasuk plastik ditempatkan pada tempat yang berbeda. Hal ini diharapkan akan terus memotivasi mahasiswa agar membuang sampah berdasarkan golongannya secara mandiri (Suryarini et al., 2019). Hal ini juga untuk meningkatkan kesadaran terhadap sampah sehingga mereka akan terlibat langsung dalam menangani persoalan sampah di daerahnya nanti (Indriyani et al., 2019).

\section{HASIL DAN PEMBAHASAN}

Kegiatan pengabdian kepada masyarakat dengan kepedulian terhadap lingkungan dari pencemaran sampah plastik di kawasan Lembanna, Tinggimoncong Kabupaten Gowa pada tanggal 20 Januari 2019 dengan jumlah peserta sebanyak 38 orang yang terdiri dari kepala lingkungan
Lembanna, mahasiswa, dan masyarakat yang ikut berpartisipasi. Mewujudkan mahasiswa yang memiliki perilaku peduli kepada lingkungan sekitar karena mahasiswa adalah agen perubahan, dan kontrol sosial ketika berada di masyarakat. Hasil dari pelaksanaan tahap persiapan dengan melakukan observasi ke kawasan Camp Lembanna diabadikan pada gambar di bawah ini.

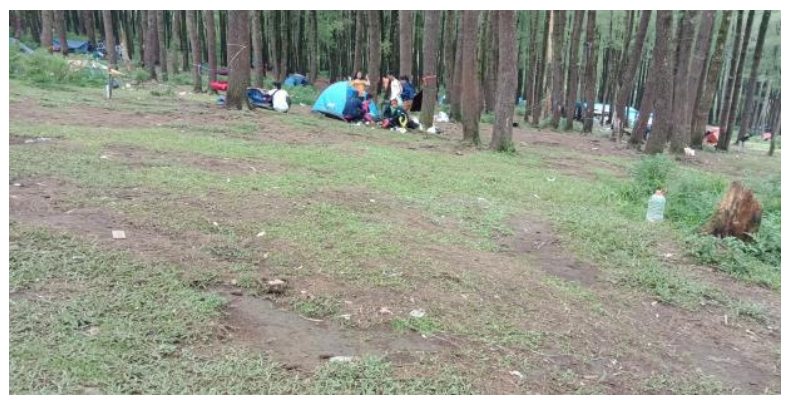

Gambar 1. Lokasi Camp Lembanna

Pada gambar 1, memperlihatkan bahwa sampah botol plastik besar dan kantong bekas makanan berserakan di mana-mana di sekitar pengunjung dan sepertinya mereka acuh akan hal itu. Sampah plastik dari berbagai macam kemasan makanan dan minuman seperti pembungkus mie, biskut, kopi saset, gelas plastik, kantong kresek, plastik bening, dan lain-lain. Inilah bentuk kurangnya kesadaran akan menjaga kebersihan agar terhindar dari pencemaran lingkungan.

Kegiatan dilaksanakan kegiatan PKM seperti itu akan menjadi solusi dengan adanya sebuah penanaman nilai untuk peduli dengan lingkungan. Seiring berkembangnya waktu isu tentang lingkungan berkembang. Ketika kita berkegiatan di alam bebas di hutan atau gunung harus menjaga kebersihan lingkungan kita berada dari sampah-sampah seperti sampah plastik, puntung rokok, kaleng bekas, botol, batu baterai, 
973 Peduli Lingkungan dari Pencemaran Sampah Plastik di Kawasan Lembanna - Rahmatia Thahir, Nurul Fadhilah, Nurdiyanti Nurul Magfirah, Anisa

DOI: https://doi.org/10.31004/abdidas.v2i4.406

dan sampah-sampah yang tidak bisa diuraikan oleh alam tidak ditinggalkan begitu saja atau membuang sembarangan melainkan dibawa kembali pulang dan dibuang di tempat sampah (Lintang, 2016).

Melalui tahap pelaksanaan penyuluhan, informasi tentang dampak pencemaran lingkungan dengan adanya sampah plastik telah disampaikan dengan membagikan brosur. Sehingga memberikan edukasi kepada mahasiswa agar berperilaku peduli dan menjaga kebersihan lingkungan dimanapun mereka berada. Tidak hanya pada saat pergi ke gunung saja, tetapi juga dalam kehidupan sehari-hari. Ketika membiasakan diri menjadi kebersihan maka kebiasaan itu akan menjadi sifat pribadi mahasiswa yang tentunya berdampak baik bagi diri sendiri. Edukasi merupakan hal yang sangat penting diberikan untuk dapat menambah pemahaman masyarakat tentang masalah pencemaran lingkungan karena sampah plastik sehingga akan sangat membantu dalam pemcegahan terjadinya masalah pencemaran.

Peserta yang memungut sampah dan mengumpulkannya pada kantong yang diletakkan pada bagian punggungnya. Peserta dilatih untuk bertanggung jawab dan peduli terhadap alam sekitar agar tetap lestari dan terjaga ekosistemnya. Sampah yang dikumpulkan setiap peserta atau peserta kemudian dikumpulkan pada wadah yang lebih besar.

Melalui kegiatan PKM akan diketahui pula adanya pertambahan pengetahuan dan kesadaran masyarakat tentang pentingnya mencegah pemcemaran sampah plastik untuk menciptakan lingkungan yang bersih, asri dan terhidar dari polusi sampah dan banjir. Sampah-sampah non organik yang bisa didaur ulang, contohnya pada plastik bekas minuman bisa dijual (Setyawan, 2016), dan menghindari kebiasaan pembakaran sampah yang menyebabkan polusi udara dan tanah (Sari \& Nofriya, 2018).

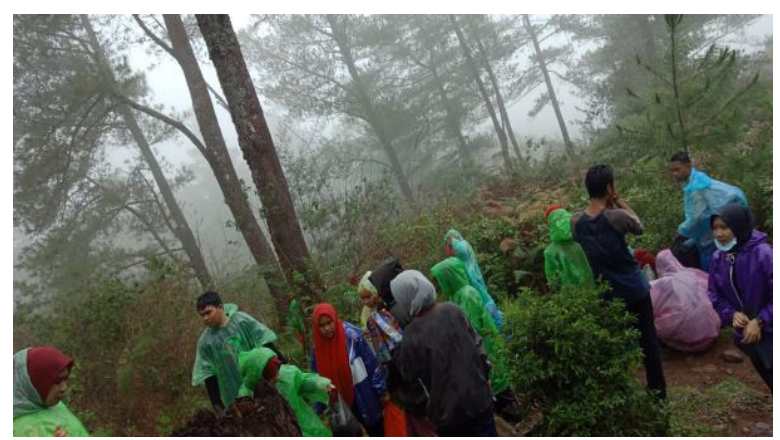

Gambar 2. Pungumpulan Sampah pada Tahap Evaluasi

Kegiatan pengabdian masyarakat ini merupakan kegiatan wajib dalam melaksanakan Tri Dharma Perguruan Tinggi yang dilakukan oleh Pendidikan Biologi Universitas Muhamamdiyah Makassar bekerjasama dengan pihak kepala lingkungan Lembanna Tinggimocong Kabupaten Gowa. Melalui pengabdian ini diharapkan masyarakat menanamkan perilaku tidak membuang sampah sembangan sehingga mencegah pencemaran lingkungan.

\section{SIMPULAN}

Berdasarkan hasil kegiatan PKM peduli lingkungan dari pencemaran sampah plastik di kawasan Lembanna dalam rangka mewujudkan masyarakat yang peduli dan sadar lingkungan menjaga kebersihan, sehingga terhindar dari pencemaran sampah plastik. Peserta sangat 
974 Peduli Lingkungan dari Pencemaran Sampah Plastik di Kawasan Lembanna - Rahmatia Thahir, Nurul Fadhilah, Nurdiyanti Nurul Magfirah, Anisa

DOI: https://doi.org/10.31004/abdidas.v2i4.406

antusias dalam kegiatan yang dilaksanakan. Dan pada kegiatan monitoring dan evaluasi terlihat adanya pengetahuan untuk memisahkan sampah plastik dan sampah bukan plastik. Untuk kegiatan penyuluhan selanjutnya, disarankan untuk melakukan edukasi lanjutan terkait pengolahan jenis sampah.

\section{UCAPAN TERIMA KASIH}

Tim penulis mengucapkan terima kasih kepada seluruh pihak yang telah membantu terselenggaranya kegiatan pengabdian kepada masyarakat ini, terutama kepada Kepala Lingkungan Lembanna, Tinggimoncong Kabupaten Gowa yang telah memberikan ijin dan memfasilitasi Tim Pelaksana PKM, serta Mahasiswa Pendidikan Biologi yang terlibat dalam kegiatan PKM ini.

\section{DAFTAR PUSTAKA}

Asmawati, S., Alni, F., Wijaya, I., Marcella, F., Ravi, A., Yulia, N., Nur, A., \& Satri, B. (2019). Pemanfaatan Limbah Plastik Dusun Butuh Ngereng-Erang Jogoprayan Gantiwarno Klaten. Prosiding Konferensi Pengabdian Masyarakat, 501-504.

Asteria, D., \& Heruman, H. (2016). Bank Sampah Sebagai Alternatif Strategi Pengelolaan Sampah berbasis Masyarakat di Tasikmalaya. Jurnal Manusia Dan Lingkungan, 23(1), 136-141. https://doi.org/10.22146/jml.18783

Indriyani, S., Dai, S., \& Isnawaty, S. (2019). Pemberdayaan Masyarakat Melalui Pengelolaan Sampah Menjadi Nilai Ekonomis dan Pembentukan Bank Sampah di Desa Pentadu Timur Kecamatan Tilamuta Kabupaten Boalemo. Jurnal Ilmiah Pangabdhi, $\quad 5(2), \quad$ 110-118. https://doi.org/10.21107/pangabdhi.v5i2.611 3
Istirokhatun, T., \& Nugraha, W. D. (2019). Pelatihan Pembuatan Ecobricks Sebagai Pengelolaan Sampah Plastik Di RT 01 RW 05 Kelurahan Kramas, Kecamatan Tembalang, Semarang. Jurnal Pasopati, 1(2), 85-90. http://ejournal2.undip.ac.id/index.php/pasopa ti

Karnelasatri. (2019). Pemanfaatan Sampah Botol Plastik Di SDN Batok 3, Tenjo, Kab. Bogor. Prosiding Konferensi Nasional Pengabdian Kepada Masyarakat Dan Corporate Social Responsibility (PKM-CSR), 706-721. https://doi.org/10.37695/pkmcsr.v2i0.554

Lintang, J. (2016). Pencinta Alam Sebagai Bentuk Peran Pemuda Di Tengah Tantangan Kehidupan Kota. Jurnal Studi Pemuda, 5(2), 447-466.

https://doi.org/10.22146/studipemudaugm.37 946

Mahyudin, R. (2017). Kajian Permasalahan Pengelolaan Sampah dan Dampak Lingkungan di TPA (Tempat Pemrosesan Akhir). Jukung (Jurnal Teknik Lingkungan), 3(1), 66-74. https://doi.org/10.20527/jukung.v3i1.3201

Sari, P. N., \& Nofriya. (2018). Pembentukan Perilaku Peduli Lingkungan Hidup Menuju Sekolah Adiwiyata pada SDN 05 Kampung Pisang Kecamatan IV Koto. Warta Pengabdian Andalas, 25(2), 10-20. http://repo.unand.ac.id/id/eprint/21753

Setyawan, P. E. (2016). Penyuluhan tentang Pengelolaan Sampah dan Pembuatan Tempat Sampah Unik dari Pipa PVC Untuk Masyarakat Desa Srigading Kecamatan Lawang. Jurnal Abdimas Unmer Malang, 1(2), 30-35. https://doi.org/10.26905/abdimas.v1i1.1172

Suryarini, A., Fatika, S., Larasaty, F. M., Yanto, Y. R., Debby, S., Deo, C., Farmasi, J., Dharma, U. S., Mesin, J. T., \& Dharma, U. S. (2019). PENINGKATAN KEPEDULIAN PEMBUANGAN SAMPAH DENGAN MEDIA SALAM BIDADARI DI SLB BANGUN PUTRA. 2(1), 24-30. https://doi.org/10.24071/altruis.2019.020104 